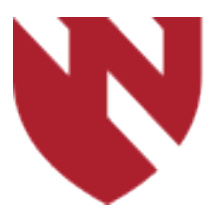

September 2020

\title{
Giant Hemorrhagic Adrenal Pseudocyst in a Postpartum Mother
}

\author{
Lucas Bohannan \\ University of Nebraska Medical Center \\ Jacob Meyer \\ University of Nebraska Medical Center \\ Sara Despain \\ University of Nebraska Medical Center
}

Tell us how you used this information in this short survey.

Follow this and additional works at: https://digitalcommons.unmc.edu/gmerj

Part of the Higher Education Commons, and the Medicine and Health Sciences Commons

\section{Recommended Citation}

Bohannan, L., Meyer, J., , Despain, S. Giant Hemorrhagic Adrenal Pseudocyst in a Postpartum Mother. Graduate Medical Education Research Journal. 2020 Sep 29; 2(1).

https://digitalcommons.unmc.edu/gmerj/vol2/iss1/41

This Conference Proceeding is brought to you for free and open access by DigitalCommons@UNMC. It has been accepted for inclusion in Graduate Medical Education Research Journal by an authorized editor of DigitalCommons@UNMC.For more information, please contact digitalcommons@unmc.edu. 


\section{Giant Hemorrhagic Adrenal Pseudocyst in a Postpartum Mother}

Creative Commons License

(c) (i) ()

This work is licensed under a Creative Commons Attribution-Noncommercial-No Derivative Works 4.0 License. 


\section{Giant Hemorrhagic Adrenal Pseudocyst in a Postpartum Mother}

Lucas Bohannan ${ }^{1}$, Jacob Meyer ${ }^{1}$, Sara Despain ${ }^{1}$

${ }^{1}$ University of Nebraska Medical Center, Department of Family Medicine

Mentor: Sara Despain

Program: Family Medicine

Type: Case Report

Background: Adrenal cysts occur more frequently in females than males, hemorrhagic adrenal cysts coinciding with parturition are exceedingly rare. These cysts often present with few or vague symptoms but are important to recognize for management as rupture could result in peritoneal seeding of cancerous tissue or even exsanguination.

Case: A 30-year-old on postpartum day one with left sided abdominal pain, a palpable mass, and 2 gram drop in serum Hgb with no typical source of postpartum hemorrhage. Ultrasound demonstrated a large fluid collection, identified as a hemorrhagic adrenal cyst on CT (Figure 1). The patient was transferred to for potential intervention including aspiration vs surgical removal. After observation her hemoglobin improved, the cyst was deemed stable, and she was scheduled for outpatient biopsy. However, it spontaneously ruptured, and the patient underwent aspiration of free serosanguinous abdominal fluid. She recovered without incident; unfortunately, the cyst reformed and ultimately, she underwent adrenalectomy.

Adrenal cysts are a rare incidental finding of $0.06-0.18 \%$ of individuals, the
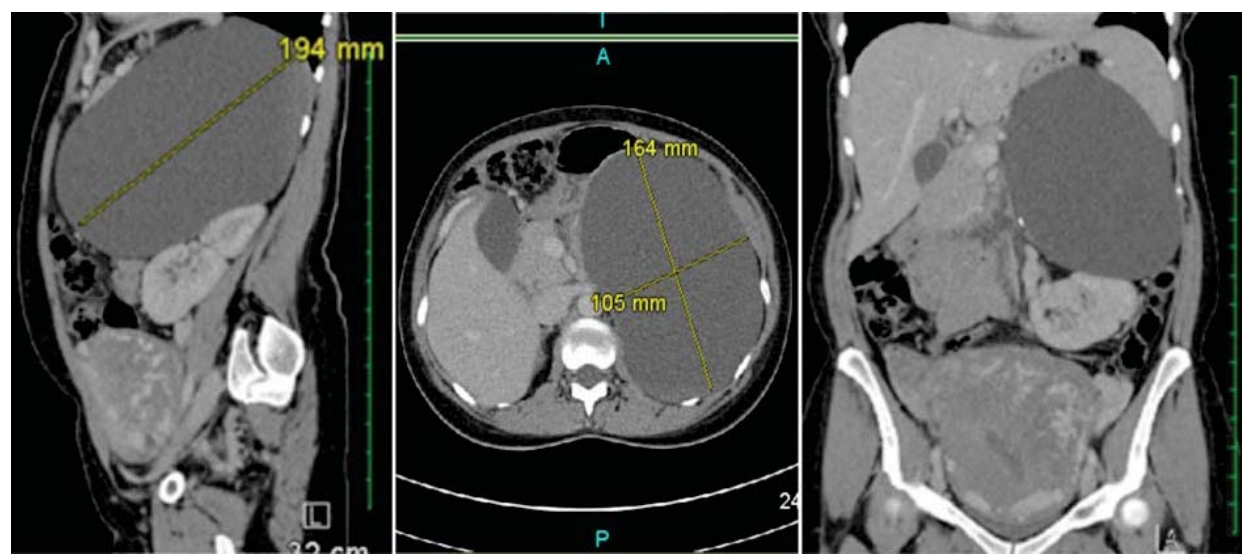

Figure 1. Giant hemorrhagic left adrenal cyst displacing left kidney inferiorly on CT scan PPD1.

overwhelming majority of which are female by a ratio of $3: 1$. Giant hemorrhagic adrenal cysts in pregnancy are astonishingly rare. Identification and proper management are paramount, because parturition represents an unpredictable situation with a potentially predictable course. Derangements of internal organs during or after delivery could result in rupture or hemorrhage. Recognizing this anticipated disturbance in pregnancy would aid in predicted course and management.

Conclusion: Hemorrhagic adrenal cysts present a difficult conundrum when it comes to management, given the lack of guidance secondary to their rarity. Conservative treatment is possible; however, providers need to continue monitoring of the cyst for complications, including rupture in the setting of labor and hemorrhage as in this postpartum complication. Primary care providers, especially those in resource poor setting should consider transfer to higher level of care.

https://doi.org/10.32873/unmc.dc.gmerj.2.1.040

\section{Risk of Prostate Cancer in U.S. Veterans With Rheumatoid Arthritis}

Kaitlyn Brittan', Punyasha Roul' ${ }^{1}$, Joshua F. Baker ${ }^{2,3}$ Brian Sauer ${ }^{4,5}$, Namrata Singh ${ }^{6,7}$, Harlan Sayles ${ }^{1}$, Grant W. Cannon ${ }^{4,5}$, Ted R. Mikuls ${ }^{1}$, Bryant R. England ${ }^{1}$

${ }^{1}$ University of Nebraska Medical Center, Department of Internal Medicine, Division of Rheumatology ${ }^{2}$ Corporal Michael J. Crescenz VA

${ }^{3}$ University of Pennsylvania

${ }^{4}$ VA Salt Lake City

${ }^{5}$ University of Utah

${ }^{6}$ lowa City VA

${ }^{7}$ University of lowa

\section{Mentor: Bryant England}

Program: Internal Medicine, Division of Rheumatology

\section{Type: Original Research}

Background: Patients with rheumatoid arthritis (RA) are at a small, but significantly increased risk of cancer compared with the general population. This risk varies by cancer type, with findings relative to prostate cancer conflicting. Recognizing the male predominance and large number of cases available in the Veterans Health System, we estimated the risk of prostate cancer in a national population of male US Veterans with RA.

Methods: We identified male patients with RA within the VA Corporate Data Warehouse $(1 / 1 / 2000-4 / 1 / 2018)$ using an algorithm adapted based on large systematic reviews. Prostate cancer and prostate cancer death were identified from the VA Oncology Raw Domain (ORD) and the National Death Index (NDI). Prostate cancer incidence rates (IR; per 1,000 pt-yrs) and 95\% CIs were calculated from the index. SIR and 95\% CI were calculated from the Surveillance, Epidemiology, and End Results Program (SEER).

Results: There were 56,764 RA patients included in analysis. Over 406,013 pt-yrs of follow-up, there were 1,433 incident prostate cancers (IR 3.53; 95\% CI 3.35-3.72 per $1,000 \mathrm{pt}$-yrs). Relative to SEER rates, SIR of prostate cancer in RA was $0.93(95 \% \mathrm{CI}$ 0.88-0.98). 